\title{
TROVADORA BEATRIZ - UM META-ROMANCE FEMINISTA
}

\author{
Ruth Röhl *
}

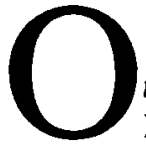

título é longo: Vida e aventuras da trovadora Beatriz segundo o testemunho de sua menestrel Laura.' E a autora, Irmtraud Morgner (1933-1989), uma das representantes da literatura feminina da ex-República Democrática Alemã.

Publicado em 1974, o romance é representativo para a literatura produzida na RDA a partir de fins da década de sessenta, literatura esta que se distancia da norma ideológico-literária até então dominante - o Realismo Socialista -, mediante abertura para a subjetividade e para a estética da modernidade.

\footnotetext{
* Universidade de São Paulo
}

1 MORGNER. Irmtraud. Leben und Abenteuer der Trabadora Beatriz nach Zengnissen ihrer Spielfrau Laura. Berlin und Weimar: Aufbau Verlag, 1974. Utilizamos neste trabalho a edição especial da coleção Luchterhand, publicada pela editora Hermann Luchterhand GmbH em 1977. A tradução é nossa.

As personagens Beatriz e Laura retomam no romance Amanda (Amanda, Ein Hexenroman, Berlin und Weimar: Aufbau-Verlag. 1983; Darmstadt und Neuwied: hermann Luchtehand Verlag GmbH \& Co KG, 1983). A temática da emancipação feminina é ai abordada de forma satírica, e a critica à realidade da RDA se toma mais contundente. As personagens são construidas segundo o principio da duplicidade; assim, a parte "inútil" de Laura se transforma em uma bruxa feminista - A manda. Laura $c$ Amanda possuem traços fisionômicos semelhantes, mas a figura da primeira parece achatada e a da segunda, alongada, como que distorcidas por um espelho mágico. Nesse livro, bruxas e hereges freqüentam montanhas mágicas onde se pode imaginar o que hoje é irrealizavel - e, como tal, é percebido como desordem -, mas que amanhã pode se tomar realidade. $O$ impossivel de hoje, o possivel de amanhã. 
Como o referencial poético da obra é o Realismo Socialista, cabe aqui um curto retrospecto. O programa do Realismo Socialista, nascido em 1932 de um encontro entre Stalin e escritores soviéticos na casa de Máximo Gorki, implica, como se sabe, uma poética normativa determinada por critérios não-estéticos. Como afirma Walter Ulbricht em 1948, essa poética tem por tarefa auxiliar o partido em sua luta pela "concretização de mudanças sociais profundas" e por uma "nova cultura progressista." A herança literária é também utilizada pela politica cultural do país estritamente na formação e desenvolvimento da consciència do povo; é posta, portanto, a serviço do desenvolvimento social e, sobretudo, económico. E essa função social que salta à vista mesmo na definição formulada por Wolfgang Heise, em 1974, quando a RDA já havia superado a fase mais difícil e se mostra mais liberal: "Entendemos, portanto, como nossa herança literária, aquelas obras e valores do passado que no contexto de vida de nossa sociedade vêm a ter uma função viva, que são usadas em um sistema de comunicaçōes estéticas determinado, em primeira instância, pelas condições socialistas." 2

A canonização do conceito de Realismo Socialista, ou seja, a transposição de um modelo de literatura do século XIX - reprodução mimética, onisciente, sem rupturas - para o século XX, foi um grande entrave para a produçāo literária da RDA. Paradoxalmente não se levou em conta nem a especificidade estética, nem a ideológica do modelo privilegiado, modelo este cunhado na literatura da época do realismo burgués e, anacrónico e incoerente com o sistema comunista. O fato é que, principalmente na fase de alicerçamento do regime socialista, trava-se um combate acirrado contra a arte chamada "formalista", contra o tipo de literatura praticada por Joyce, Proust ou Kafka, e que era vista como reflexo da decadéncia burguesa. Só a partir da década de sessenta é que esses autores começam a ser publicados na RDA.

Uma postura mais ousada por parte dos escritores delineia-se em fins dos anos sessenta. Alguns criticos vêem o ano de 68 como decisivo, interpretando essa atitude como uma reação à invasão da Tchecoslováquia por tropas soviéticas. O pais vive um novo momento de sua história, o da "construção do socialismo amadurecido ou desenvolvido", conforme Leonid Brejnev no VIII Encontro do partido SED, em 1971. No campo da teoria literária questiona-se o conceito de Realismo Socialista e a estécica

2 DAHNKE, Hans-Dietrich Erbe und Tradition in der Literatur. Leipzig: VEB Bibliographisches Institut, 1977. p. 62. 
marxista, para muitos anacrônica, impondo-se a busca por novos caminhos. $O$ interesse diferenciado, por parte dos autores, e a existência de um contexto social com necessidades outras possibilitam a aproximação a parcelas da tradiçāo que de inicio haviam sido postas de lado. Um exemplo é o Romantismo. Rejeitado devido à grande recepção que obtivera por parte de forças reacionárias, como no Terceiro Reich, o Romantismo é redescoberto na década de setenta. A consequiência prática é o surgimento de uma vertente literária que privilegia a interioridade, a busca de autoconhecimento, a análise psicológica e, evidentemente, a exposição de conflitos.

Considerando-se a especificidade do contexto literário da RDA, é elucidativa a seguinte discussão sobre realidade e fantasia, utopia e fuga, relatada da perspectiva de uma mulher, que se encontra à página 218 do romance: "Ele disse: 'Idéias fantasiosas são uma fuga, sinal de capitulação." Eu disse: 'Pelo contrário, são sinal de soberania. Sim, de um agir soberano com os objetos da realidade, como fazem as crianças, por exemplo, em seus desenhos. "Mas isso denota conflito", retrucou Uwe. Eu dei razão a ele. 'Um conflito entre expectativa e realidade', disse Uwe com perspicácia. E eu o deixci completamente confuso, quando também ai lhe dei razão. E então ele também não hesitou em suspeitar de mim. Como de alguém, por assim dizer, de duas caras, pois, segundo ele, eu tinha considerado o socialismo a melhor coisa que havia, e a mim, uma utopista. A contradiçāo era evidente e absoluta. Uwe passou à prova com a definição: 'Utópica é uma consciência que não se acha em congruência com a vida em torno. 'Meus contos de fada, ele os chamou de 'antiimagens'. Eu the respondi, por exemplo que meus contos de fada eram atos, não modelos. 'Sucedâneos', interrompeu aos gritos. 'Não', revidei. 'São provas de amor', gritei, 'por você, porque quero ser justa para com você e sua espécie; para isso é preciso ter força, para paciência $\mathrm{c}$ justiça histórica $\dot{e}$ preciso ter muita força, meu caro, sua negligência e sua comodidade ingênua custam-me, pelo menos, uma segunda jomada diária, que me exacerbaria como cientista, se eu não pudesse me suster nessa certa tensão utópica. Talvez cla seja até mesmo uma espécie de auxílio à vida, mas uma espécic ativa, não comparável à religião ou a um sucedâneo de religiāo, que vocế pratica, talvez ainda continue praticando, pelo menos é o que pensa o meu pai. Se cu quero ser justa do ponto de vista da história, não posso responsabilizá-lo por seus hábitos morais, eles são a norma vigente. Mas também não posso responsabilizar o nosso Estado, senão minha vista ficaria tapada para as grandes melhorias que ele conseguiu realizar em apenas vinte e cinco anos; isto $\dot{e}$, basicamente eu preciso me 
conformar com a minha situação. E isso eu também faço, ninguém pode se retirar da história, eu me conformo. Mas não passivamente. Isto seria o meu fim. Sem a tensão, que às vezes crio para mim, para refrigério do corpo e da alma, no verso de manuscritos, eu seria cientificamente uma voz vazia. Meu otimismo vive dessa tensāo entre os pólos realidade e comunismo - minha jovialidade; sem essa tensão eu perderia a capacidade de amar homens."

$O$ romance Vida e aventuras da trovadora Beariz segundo o testemunho de sua menestrel Laura faz parte do processo literário da RDA e atesta, pudemos ver, a rebeldia de Irmtraud Morgner em relação à poética adotada, poética centrada no herói positivo e em uma realidade marcada pela inexisténcia de conflitos. Ele se compõe de treze livros e sete intermezzos; começa com a relação das personagens principais e uma observação ao leitor: a estrutura do romance é recomendada mas não imposta, donde a síntese no final do livro. Na breve introduçāo que segue, assinada por Irmtraud Morgner, ja se caminha em via de mão dupla, orientada de um lado pela fantasia e, de outro, pela realidade.

Iniciando com a frase "Sem dúvida o pais é lugar do maravilhoso", Irmtraud Morgner descreve seu encontro com uma mulher de nome Laura, que the propōe a compra de manuscritos que iriam lhe poupar "uma dezena de viagens, uma centena de esboços de textos e milhares de conversas". Tratava-se de registros da vida e das aventuras de Beatriz de Dia, trovadora que acabara de falecer em Berlim Oriental, aos 843 anos, de quem Laura fora menestrel. Encantada com o fabuloso achado, Morgner decidira-se a publicá-lo; sua versio é fiel a fonte, mudara apenas a ordem dos textos, em atenção ao leitor. Conclui relatando a visita que fez ao crematório do Baumschulenweg, em Berlim Oriental, onde teve a oportunidade de contemplar a fisionomia da trovadora.

A trama do livro retoma o gesto narrativo do romance picaresco e vai tecendo um universo onde convivem o fantástico, o mitológico e o cotidiano socialista. Ao decidir-se a abandonar o mundo dos homens de seu tempo, a trovadora Beatriz é auxiliada por Perséfone, que lhe concede um sono de oitocentos anos em troca de trabalho em prol da reinstauraçāo do matriarcado. Beatriz repete a história da Bela Adonnecida: pica o dedo no fuso de uma roca e adormece, despertando no ano de $1968 \mathrm{com}$ as imprecatçōes de um engenheiro civil que "tropeça" no castelo coberto por heras. A revolta estudantil de 68 é uma das vivências da trovadora, que também experimenta as novidades dos tempos modemos: anda de carona, toma LSD, trabalha num espetáculo de strip-tease, etc. Casa-se em Paris e torna-se amante de 
Alain, estudante em cuja companhia "aprende alemão e Marx", requisitos que a habilitam a aceitar um convite para visitar a RDA. Mais que os elogios tecidos a esse pais, o que a move à viagem é a afirmação de que também os expropriados e as mulheres têm o direito de serem registrados na história: "'Pois os expropriados e as mulheres, que até agora não foram considerados dignos de serem inscritos na história, nem por isso estão automaticamente sem história', disse Parnitzke ameaçador. 'Não se pode criar ou eliminar a realidade com palavras, mas se pode silenciá-la. Precisamos romper esse silèncio." (p.67).

Os restantes dois terços do romance tratam, com muito humor c ironia, dos caminhos e descaminhos da trovadora na "terra prometida" (e cm outros países, que visita à procura de um unicórnio). Morre em decorrência do entusiasmo desmedido que a invade, quando a vitória dos partidos de esquerda nas eleiçōes de 1973 na França. O romance termina como começa, ou seja, retomando o primeiro capítulo do primeiro livro; esse final evoca, porém, um fluxo sem fim, e uma vitória do discurso da mulher, pois é um homem, o marido de Laura, que narra a esta - em estilo "beatricio" - a primeira de "mil e uma histórias". As últimas frases mostram o efeito fantástico da presença da trovadora na RDA, e as últimas palavras são uma variaçāo das primeiras: "Pois sem dúvida o pais era lugar do maravilhoso".

Os poucos dados sobre a trovadora provençal, mencionados no romance, são absolutamente corretos. Beatrix ou Béatrice, condessa de Die, esposa de Guillem de Poitiers, foi a primeira das trobairitz. Viveu no século XII, e de suas cançōes de amor, dedicadas a Raimbaut d'Aurenga, poeta de rimas "claras" $\mathrm{e}$ "obscuras", restam apenas cinco, escritas num estilo simples e num tom apaixonado. A primcira estrofe de uma delas - Plaintes d'une amante dédaignée -, talvez a mais conhecida, é citada à página 96 do romance, na tradução para o alemão de Franz Wellner:

" $\mathrm{Zu}$ singen kommts mich an, wie ichs auch wehre.

So qual ich mich um ihn, des ich begehre, nach dem ich mich wie sonst nach nichts verzehre.

Nicht, wie in artger Huld ich ihm gewogen, nicht Rang noch Geist noch Schönheit achtet er.

Er lässt mich stehn, verraten und betrogen, wie ichs vendient, wenn ich ein Scheusal wär..."

(A chantar m'er de so qu'ieu no volria, Tan me rancur de lui cui sui amia Car eu l'am mais que nuilla ren que sia; Val lui no'm val merces ni contesia, 
Ni ma beltatz, ni mos pretz, ni mos sens,

C'atressi 'm sui enganad' e trahia

Cum degr"esser $s^{*}$ ieu fos desavinens.

Il me faut chanter d"autre sonte que je ne le voudrais, puisque $\mathrm{j}^{\prime}$ ai à me plaindre de celui que $\mathrm{j}$ 'aime; car je l"aime plus que tout au monde.

Aupres de lui ne $m$ aadent ni merci ni cournoisie, ni ma beauté, ni mon prix, ni mon esprit:

me voici dono trompée et trahie comme si j"étais deplaisante!

A trovadora Beatriz não é a única personagem feminina responsável pelo maravilhoso. Marie von Lusignan, chamada de "a bela Melusine", $c$ igualmente auxiliada por Perséfone. Feminista e leitora assídua de livros políticos, escapa da mone na fogueira transformando-se em um ser alado, metade mulher e metade dragão. Enquanto a trovadora dorme seu sono de Bela Adormecida, a feminista trava, ao longo de séculos, uma luta renhida c sem grande sucesso pela vitória dos valores femininos.

As aventuras da trovadora que torna à vida após um sono de séculos, história nascida do "espírito da emancipaçāo feminina socialista e do movimento de 68 ", como diz. Genia Schulz, ${ }^{4}$ mostram que, na literatura da RDA, a abertura para a estética da modernidade caminha pari passu com uma maior consciēncia critica para o papel da mulher na sociedade socialista. Na verdade, várias escritoras vèm desempenhando um papel importante na conquista dessa nova sensibilidade, seja buscando uma maior compreensão e autoconsciència, seja tematizando o próprio corpo e a própria sexualidade. $O$ fato $\dot{e}$ que, embora vivendo em um sistema que assegura ideologicamente a emancipação feminina e a participação da mulher no discurso cultural, Irmtraud Morgner aponta contradiçōes no cotidiano socialista da mulher na RDA, e o faz com tal eficácia, que o romance Vida e aventuras da trovadora Beatriz segundo o testemunho de sua menestrel Laura é referido, pelo jornal "Frankfurter Rundschau", como uma espécie de "Bíblia da emancipação feminina atual".

É preciso, no entanto, levar em conta a especificidade da literatura feminina produzida na ex-RDA. A crítica literária da RDA geralmente insere p. 66 × $68 / 69$.

3 JEANROY, Alfred. Anthologie des Troubadours. Paris: Librairie A.-G. Nizet, 1974. 4 SCHULZ, Genia. "Kein Chorgesang. Neue Scheibweisen bei Autorinnen (aus) der DDR". In ARNOLD. Heinz Luduig (ed.): Bestandsaufiahme Gegemwansliteratur. München: edition text + kritik GmbH, 1988. p. 214. 
a literatura feminina num contexto mais amplo, indicando como ponto de partida de seu universo ficcional a derrota do sexo feminino quando da passagem do matriarcado às primeiras sociedades de classe patriarcais, e mesmo remetendo à história universal da cultura e da barbárie. ${ }^{5}$ Referindose à quantidade de livros escritos por mulheres e da perspectiva da mulher, publicados na RDA em inícios de setenta, Eva e Hans Kaufmann, críticos literários da lá, acentuam a filiação socialista dessas obras, afirmando que a emancipação da mulher, enquanto tema e tendência, é sintoma de uma maior participação da mulher na luta por emancipação no sentido mais amplo, no sentido marxista do conceito. ${ }^{6}$ Thomas Koebner, da RFA, também é da opinião que, na literatura da RDA, a emancipação da mulher está ligada à emancipação da sociedade em geral, lembrando que a voz feminina na literatura da RDA dos últimos vinte anos geralmente expressa o desejo de harmonização entre individuo e sociedade, entre a retórica progressista e a realidade.

O principio que rege a estrutura do romance é o da montagem, a "forma do romance do futuro", como se lê à página 169. O motivo da opção essa forma é simples: é a que mais se adapta ao ritmo da mulher, sempre interrompida por afazeres domésticos. O trecho metapoético a que nos referimos inclui considerações sobre prosa curta e participação do leitor: "A forma ortodoxa do romance exige fidelidade a uma concepção por vários

5 Cf. PLESSKE, Gabriele. "Das feme Mass der Harmonie". In RICHTER, Hans (ed.): Generarionen Temperamente Schreibweisen. Halles, Leipzig: Mitteldeutscher Verlag, 1986. p. 223 e 226.

6 Cf. KAUFMANN, Eva e Hans. Enwartung und Agebot. Berlin: Akademie-Verlag. 1976. p. 233. Os autores dāo destaque às escritoras Brigitte Reimann, Irmtraud Morgner, Gerti Tetzner, Christa Wolf e Sarah Kirsch

Os autores se posicionam claramente à página 187: "Essa acentuação talvez tenha algo de chocante; ela pode despertar a suspeita de que devam ser instauradas aqui uma literatura 'masculina' e uma literatura 'feminina'. E é de se suspeitar quando manifestações sociais são reportadas a conceitos antropológicos ou biológicos como, por exemplo, à questāo da diferença de geraçōes ou à do sexo. A fisionomia da literatura contemporanea da RDA aponta, contudo, inequivocamente tais acentos distintos. Porém, da mesma forma como não se pode chamar as estorias de Volker Braun de literatura 'masculina', também não se pode dizer que os livros citados, eseritos por mulheres, sejam literatura 'feminina' no sentido de estarem voltados para uma esfera especificamente feminina, separada dos interesses da sociedade em geral. São obras socialistas, que se destinam a todos que as queiram ler. Elas não defendem interesses sociais distintos do socialismo, embora chamem a atenção para o fato de, nesse contexto, não se acharem totalmente resguardados os interesses dos individuos".

7 Cf. KOEBNER, Thomas. "Dic zeitgonössische Prosa II: Erfahrungssuche des Ich. Perspektiven des Erzählens seit 1968". In KOEBNER, Thomas (ed.): Tendenzen der deutschen Gegemwartiteratur. Stuttgart: Alfred Kröner Velag, 1984. p. 229. 
anos. Em face dos intensos movimentos políticos no mundo inteiro e da imensa onda de informaçāo, hoje em dia isto só pode ser levado a termo com sucesso por temperamentos lentos ou obstinados. O que eu ofereço é a forma do romance do futuro. Que pertence ao gênero operativo. (...) Para Beatriz, escrever é um processo experimental. Prosa curta é ar comprimido, se trabalha com intensidade e muito afinco. Não levando em consideração o temperamento, prosa curta corresponde ao ritmo de vida, condicionado pela sociedade, não biologicamente, de uma mulher comum, cuja atenção é constantemente desviada por estorvos de ordem doméstica. Falta de tempo e interferencias imprevisiveis obrigam a lances rápidos, sem sintonização sucessivas; cu só consigo começar a escrever em entrega total, ou não. (...) A leitura deve ser um trabalho produtivo: prazer. Só se pode escrever histórias curtas em cumplicidade com o leitor. Cabe a ele a tarefa de completar a totalidade. O gènero conta com a produtividade do leitor. Prosa curta dá o pormenor, o detalhe. E isso. Exatidāo de detalhes pesa mais do que colossalidade, se vaga. E ela tem de ser vaga, pois não se pode forçar a epopéia. Esta precisa crescer aos poucos. $\mathrm{Na}$ arte, nada pode ser forçado. Ela è algo vivo."

Na obra em questāo, a montagem facilita sobretudo o pastiche de estilos e gèneros literários, a mescla entre realidade e ficção, reflexão e fantasia, poesia e metapoesia. Através dessa espécie de mosaico, tem-se um panorama vazado sob uma ótica crítica. $\mathrm{A}$ imagem da RDA nāo aparece distorcida pela ideologia de um herói positivo ou de um mundo sem conflitos, como no Realismo Socialista, mas com todas as suas contradiçōes. As dificuldades vividas nos anos de reconstrução do país e de alicerçamento do socialismo, os efeitos do controle e da censura ideológica no comportamento das pessoas e no sistema editorial, a restrição especial aos limites geográficos do pais são alguns dos problemas ai ventilados e, ao mesmo tempo, relativizados pelo humor. Na verdade, Morgner usa a história do sexo feminino como pretexto, ou melhor, um "pré-texto": a guerra dos sexos, a luta pela emancipação da mulher se dão no espaço social e têm por pano de fundo todo um panorama histórico-cultural, o que faz com que o romance realmente transcenda os limites da literatura feminista.

A postura subversiva de Irmtraud Morgner é também perceptivel no tratamento - irreverente - que às vezes dispensa à herança cultural e, acima de tudo, na desautorização da voz autoral. O que mais chama a atenção nessa obra é o quebra-cabeça construído em tomo da autoria dos fragmentos. A "cópia" é o procedimento por excelência do romance e é tema da entrevista 
registrada às páginas 313 e 314 . Os sete intermezzos contêm, por exemplo, trechos do romance Rumba a um outono (escrito por Irmtraud Morgner em 1965 e não publicado devido à censura) que a bela Melusine copia em seus "livros melusínicos"; os treze livros também contêm capítulos "copiados" pela bela Melusine das mais diversas fontes, desde jornais e revistas até anotaçōes (de Laura) e outras obras. Os capítulos que giram em torno das aventuras da trovadora Beatriz mesclam-se a relatos, contos, histórias para televisão, etc., escritos e/ou plagiados por essa e outras personagens, bem como a cartas, entrevistas e discursos, fictícios ou não, atribuídos a personagens da vida real (à própria Irmtraud Morgner, à poetisa Sarah Kirsch, ao Ministro da Saúde da RDA, etc.).

Apenas dois exemplos. O quarto capítulo do quarto livro traz o título "Onde se reproduz, nas palavras e no modo de ver da trovadora, o que o motorista do carro oficial conta a esta, durante o percurso, como sendo história de um amigo seu". E o título do sexto livro informa também do plágio: "Conto de amor de Laura Salman, que Beatriz de Dia lê para treze funcionários e sete funcionárias do metrô de Berlim como obra de sua autoria". Vários autores da RDA são "copiados" ao longo do romance, como Peter Hacks e Volker Braun. É deste último, por exemplo, a "Canção do Comunismo", enviada pela trovadora à bela Melusine em lugar de uma canção de protesto de lavra própria.

A brincadeira com a dissolução da consciência unificadora do romance torna-se, às vezes, um verdadeiro jogo de esconde-esconde. É o caso dos escritos póstumos de Valeska Kantus - "Paralipômenos a um homem" -, traduzidos da língua do Hades por Beatriz de Dia, que se encontram registrados no verso de um artigo cientifico atribuido a Rudolf Uhlenbrook, o qual, por sua vez, "talvez não passe de uma ficção de Valeska".

Abolindo o mito do autor, o romance vivencia o processo de criação como mero deslocamento da linguagem de um espaço para outro.

Além do mais, as citações e alusões a textos literários geralmente estão dentro de um contex to irônico ou inusitado, engraçado, o que faz com que a literatura seja vista pelo leitor não com um aura de seriedade, mas $\mathrm{em}$ seu aspecto lúdico, como diversão. A menção às cinco canções de amor de Beatriz de Dia deve-se, por exemplo, ao ato da trovadora de, quando de volta à vida, copiá-las de uma antologia e enviá-las ao "Paris-Match". Como se 
pode ver, humor e ironia, irreverencia e engenhosidade fazem do "plagiarism" um verdadeiro playgiarism, como manda a estética pósmoderna ${ }^{8}$.

Assim é que Vida e aventuras da trovadora Beatriz segundo o testemunho de sua menestrel Laura pode ser considerado um metaromance? feminista: tendo como referencial o Realismo Socialista, ele não só incorpora, como também elabora, em reflexões poetológicas, a estética da modernidade, até mesmo o momento pós-moderno. A subversāo do cânon literário se faz visível na poética de ruptura que segue - ruptura pelo humor, pela ironia, pelo estranhamento, pela metapoesia. Feminismo e modernidade, num livro que é um convite à leitura.

\section{RESUMO}

O romance Vida e aventuras da trovadora Beatriz segundo o testemunho de sua menestrel Laura, de Imntraud Morgner, caracteriza-se por uma postura crítica face à realidade da República Democrática Alemã, bem como por traços narrativos modemos, como por exemplo montagem de textos - em parte documentais, em parte fictícios - e auto-reflexão sobre o processo de nartar. Este trabalho examina o romance à luz do Real ismo Socialista e da abertura para a estética da modernidade.

\section{KURZFASSUNG}

Der Roman Leben und Abenteuer der Trobadora Beatriz nach Zeugnissen ihrer Spielfrau Laura, üon Irmtraud Morgner, kennzeichnet sich durch eine kritische Haltung gegenŪber der Realitāt der Deutschen Demokratischen Republik, sowie durch moderne Erzählmittel, wie z B. Montage von Texten - teils dokumentarisch, teils fiktiv - und Selbstreflexion auf den Schreibprozess. Der hier vorgelegte Aufsatz untersucht diesen Roman im Hinblick auf den Sozialistischen Realismus und die Aneignung der Ästhetik der Modernität.

8 Cf. FEDERMAN, Raymond. "Imagination as Plagiarism (an unfinished paper...)" In: New literary History (3), 1976. p. 565. 